\title{
Fluvoxamine for symptomatic outpatients with COVID-19
}

\author{
Peter E. Wu MD MSc, Emily Austin MD, Derek Leong RPh BScPhm
}

Cite as: CMAJ 2022 February 22;194:E258. doi: 10.1503/cmaj.220011; early-released January 19, 2022

1

\section{Fluvoxamine may prevent hospital admission in symptomatic} adults with COVID-19

Fluvoxamine is a selective serotonin reuptake inhibitor with potential antiinflammatory and antiviral properties. ${ }^{1}$ A meta-analysis of 2196 patients with COVID-19 from 3 randomized controlled trials concluded that fluvoxamine had a high probability of preventing hospital admission or observation in the emergency department for more than 24 hours, compared with placebo. ${ }^{2}$ The Ontario Science Table states that fluvoxamine may be considered for mildly ill patients within 7 days of symptom onset. ${ }^{3}$

2

\section{Children and pregnant people have not been studied}

Trials primarily enrolled unvaccinated adult outpatients at high risk for serious COVID-19 outcomes. ${ }^{2}$ For pregnant patients, caution and obstetrical consultation are advised. Fluvoxamine is not recommended for pediatric patients. Patients on a serotonergic antidepressant for a psychiatric condition who are switched to fluvoxamine may experience decompensation in their mental health.

\section{3}

\section{Fluvoxamine was generally well tolerated in the clinical trials}

Treatment was either $100 \mathrm{mg}$ twice daily for 10 days, or started at $50 \mathrm{mg}$ once daily, titrated to $100 \mathrm{mg}$ twice daily over 2-3 days, and up to 3 times daily as tolerated for a total of 10-15 days. ${ }^{2}$ Treatment ended without taper. ${ }^{2}$ Patient-reported adverse events were similar in the fluvoxamine and placebo groups, and included mild headache and gastrointestinal symptoms. ${ }^{2}$

\section{Food and drug pharmacokinetic interactions can occur}

Fluvoxamine inhibits multiple cytochrome (CYP) P450 isoforms, especially CYP1A2 and CYP2C19. ${ }^{4}$ Caffeine and warfarin are metabolized primarily or in part by CYP1A2.,5 Caffeine intake should be limited to 1 serving per day. Patients on warfarin should have international normalized ratio (INR) checks every 3-5 days during and after fluvoxamine use, particularly if the warfarin dose is changed. Clopidogrel is activated in part by CYP2C19 and fluvoxamine may therefore reduce its efficacy, a particular risk for patients with a recent ischemic stroke or cardiac stenting. ${ }^{6}$

Fluvoxamine use can result in pharmacodynamic adverse reactions Adding fluvoxamine to other serotonergic antidepressants or monoamine oxidase inhibitors increases the risk of serotonin syndrome. ${ }^{4,6}$ Fluvoxamine prolongs the QTc interval, and use with other QTc-prolonging medications increases the risk of torsades de pointes. ${ }^{4,6}$ Some medications are critical to a patient's care or have a very long half-life; temporarily stopping those drugs may cause harm (list of interactions included in Appendix 1, available at www.cmaj.ca/lookup/doi/10.1503/cmaj.220011/tab-related-content).

\section{References}

1. Sukhatme VP, Reiersen AM, Vayttaden SJ, et al. Fluvoxamine: a review of its mechanism of action and its role in COVID-19. Front Pharmacol 2021;12:652688.

2. Lee TC, Vigod S, Bortolussi-Courval É, et al. Fluvoxamine for outpatient COVID-19 to prevent hospitalization: a systematic review and meta-analysis. medRxiv 2021 Dec. 21. doi: 10.1101/2021.12.17.21268008.

3. Kellar J, Wu P, Reiersen A, et. al. Ontario COVID-19 Drugs and Biologics Clinical Practice Guidelines Working Group, University of Waterloo School of Pharmacy. Fluvoxamine: What prescribers and pharmacists need to know. Version 1.0 Ontario COVID-19 Science Advisory Table. 2022;3(54). Available: https://covid19 -sciencetable.ca/sciencebrief/fluvoxamine-what-prescribers-and -pharmacists-need-to-know/ (accessed 2022 Jan. 12).

4. Spina E, Trifirò G, Caraci F. Clinically significant drug interactions with newer antidepressants. CNS Drugs 2012;26:39-67.

5. Culm-Merdek KE, von Moltke LL, Harmatz JS, et al. Fluvoxamine impairs single-dose caffeine clearance without altering caffeine pharmacodynamics. Br J Clin Pharmacol 2005;60:486-93.

6. Luvox product monograph. Etobicoke (ON): BGP Pharma ULC; revised 2016 July 6. Available: https://www.mylan.ca/-/media/ mylanca/documents/english/product\%20pdf/luvox-pm-2016 -07-06.pdf (accessed 2022 Jan. 10).

Competing interests: Peter Wu is a volunteer member of the Ontario COVID-19 Drugs and Biologics Clinical Practice Guidelines Working Group, and is a coauthor on the Science Table Clinical Guideline titled Fluvoxamine: what prescribers and pharmacists need to know. No other competing interests were declared.

This article has been peer reviewed.

Affiliations: Division of General Internal Medicine and Geriatrics (Wu), University Health Network; Division of Clinical Pharmacology and Toxicology (Wu), Department of Medicine, University of Toronto; Division of Emergency Medicine (Austin), St. Michael's Hospital; Ontario Poison Centre (Austin), Hospital for Sick Children; Department of Pharmacy (Leong), University Health Network, Toronto, Ont.

Content licence: This is an Open Access article distributed in accordance with the terms of the Creative Commons Attribution (CC BY-NC-ND 4.0) licence, which permits use, distribution and reproduction in any medium, provided that the original publication is properly cited, the use is noncommercial (i.e., research or educational use), and no modifications or adaptations are made. See: https://creativecommons.org/ licenses/by-nc-nd/4.0/

Correspondence to: PeterWu, peter.wu@uhn.ca 